\title{
Meta-analysis of gene expression in relapsed childhood B-acute lymphoblastic leukemia
}

Yock-Ping Chow ${ }^{1}$, Hamidah Alias ${ }^{1,2}$ and Rahman Jamal ${ }^{1,2^{*}}$

\begin{abstract}
Background: Relapsed pediatric B-acute lymphoblastic leukemia (B-ALL) remains as the leading cause of cancer death among children. Other than stem cell transplantation and intensified chemotherapy, no other improved treatment strategies have been approved clinically. Gene expression profiling represents a powerful approach to identify potential biomarkers and new therapeutic targets for various diseases including leukemias. However, inadequate sample size in many individual experiments has failed to provide adequate study power to yield translatable findings. With the hope of getting new insights into the biological mechanisms underpinning relapsed ALL and identifying more promising biomarkers or therapeutic targets, we conducted a meta-analysis of gene expression studies involving ALL from 3 separate studies.

Method: By using the keywords "acute lymphoblastic leukemia", and "microarray", a total of 280 and 275 microarray datasets were found listed in Gene Expression Omnibus database GEO and ArrayExpress database respectively. Further manual inspection found that only three studies (GSE18497, GSE28460, GSE3910) were focused on gene expression profiling of paired diagnosis-relapsed pediatric B-ALL. These three datasets which comprised of a total of 108 matched diagnosis-relapsed pediatric B-ALL samples were then included for this meta-analysis using RankProd approach.

Results: Our analysis identified a total of 1795 upregulated probes which corresponded to 1527 genes (pfp < 0.01; $F C>1$ ), and 1493 downregulated probes which corresponded to 1214 genes (pfp $<0.01 ; F C<1$ ) respectively. S100A8 appeared as the top most overexpressed gene ( $\mathrm{pfp}<0.01, \mathrm{FC}=1.8$ ) and is a potential target for further validation. Based on gene ontology biological process annotation, the upregulated genes were most enriched in cell cycle processes (enrichment score $=15.3$ ), whilst the downregulated genes were clustered in transcription regulation (enrichment score = 12.6). Elevated expression of cell cycle regulators (e.g kinesins, AURKA, CDKs) was the key genetic defect implicated in relapsed ALL, and serve as attractive targets for therapeutic intervention.
\end{abstract}

Conclusion: We identified S100A8 as the most overexpressed gene, and the cell cycle pathway as the most promising biomarker and therapeutic target for relapsed childhood B-ALL. The validity of the results warrants further investigation.

Keywords: Pediatric B-acute lymphoblastic leukemia, Relapse, Microarray, Gene expression

\footnotetext{
* Correspondence: rahmanj@ppukm.ukm.edu.my

'UKM Medical Molecular Biology Institute (UMBI), Universiti Kebangsaan

Malaysia Medical Center, 56000 Cheras, Kuala Lumpur, Malaysia

${ }^{2}$ Department of Pediatric, Faculty of Medicine, National University of

Malaysia, Universiti Kebangsaan Malaysia Medical Center, 56000 Cheras, Kuala

Lumpur, Malaysia
}

(c) The Author(s). 2017 Open Access This article is distributed under the terms of the Creative Commons Attribution 4.0 International License (http://creativecommons.org/licenses/by/4.0/), which permits unrestricted use, distribution, and reproduction in any medium, provided you give appropriate credit to the original author(s) and the source, provide a link to the Creative Commons license, and indicate if changes were made. The Creative Commons Public Domain Dedication waiver (http://creativecommons.org/publicdomain/zero/1.0/) applies to the data made available in this article, unless otherwise stated. 


\section{Background}

B-Acute lymphoblastic leukemia (ALL) accounts for $80 \%$ of childhood leukemias, and relapsed B-ALL remains as the leading cause of cancer related deaths among children $[1,2]$. Despite the 5-year survival rate for pediatric ALL exceeding $90 \%$ after treatment with multi-agent chemotherapy tailored to established risk factors [3], nearly 20\% of patients will still relapse and succumb to disease. Relapsed B-ALL has a dismal prognosis, with overall survival rates of $35-40 \%$ even when treated with intensified chemotherapy or stem cell transplantation [4-6]. To date, the biological mechanisms of relapsed ALL remains largely unknown. Therefore, there is a pressing need to gain better understanding of the molecular mechanisms governing relapsed ALL, with the hope of developing more effective treatment plans and to improve patients' survival rate.

In the past decades, microarray has been widely used to identify candidate biomarkers and therapeutic targets by studying the gene expression changes at the genome wide level. Several studies on diagnosis-to-relapsed ALL have been performed to unlock the dysregulated genes and pathways essential in driving relapsed ALL [7-10]. However, only a very small number of genes were found significantly differentially expressed between diagnosis and relapse, and the results were not consistent across all these studies. These discordant results therefore have limited the reliability for further validation or development into clinically useful biomarkers and therapeutic targets. It has been well recognized that small sample sizes, different microarray platforms, and different statistical methods are among the limiting factors contributed to the discordant results. To resolve this limitation, meta-analysis represent a powerful approach to combine different datasets from different studies to improve the reliability and generalizability of the findings by increasing its statistical power analysis. Meta-analysis on gene expression data has yielded new biological insights, as well as identification of more robust and reliable candidate biomarkers and therapeutic targets [11-13].

To identify differentially expressed genes across multiple datasets, we employed a non-parametric 'rank product' method $[14,15]$. RankProd is among the most popular tool which utilizes a non-parametric statistical method and outperforms other meta-analysis methods, including metaArray [16], GeneMeta [17], and MAMA [18], by ranking the differentially expressed genes based on false discovery rate. Matched diagnosis and relapse samples represent the most ideal biological samples to study the mechanisms for relapse. Hence, in this study, we sought to identify differentially expressed genes associated with relapsed ALL by performing a meta-analysis on three independent microarray datasets of paired diagnosis-relapsed B-ALL, with the hope of providing new insights into the molecular mechanisms of relapsed B-ALL, as well as to identify potential therapeutic options to improve patients' outcome. Interestingly, our analysis found a long list of significantly differentially expressed genes which have been missed in individual studies, and highlighted cell cycle regulators as promising therapeutic targets amenable for relapsed childhood B-ALL.

\section{Methods}

\section{Selection of microarray datasets}

To identify paired diagnosis-relapsed pediatric B-ALL microarray expression datasets for meta-analysis, we performed a web-based search in Gene Expression Omnibus database GEO (http://www.ncbi.nlm.nih.gov/geo) and ArrayExpress (http://www.ebi.ac.uk/arrayexpress) database using the keywords "acute lymphoblastic leukemia", and "microarray". A total of 280 and 275 expression by array datasets were listed in GEO and ArrayExpress databases respectively (before $6^{\text {th }}$ March 2015). The datasets were reviewed manually and only datasets which fulfilled the following criteria were included for further analysis: (1) Expression profiling by array, (2) Studies which comprised of CEL raw files, and (3) Paired diagnosis-relapsed pediatric B-ALL samples. Only 3 microarray datasets were found, in which GSE28460 and GSE18497 were listed in GEO, whilst GSE28460, GSE18497, and GSE3910 were recorded in ArrayExpress. All three microarray datasets were included in this meta-analysis. GSE3910 consisted of 32 matched diagnosis-relapsed ALL using the using the Affymetrix Human Genome U133A Array [8], whilst GSE18497 [9] and GSE28460 [7] were generated using Affymetrix Human Genome U133 Plus 2.0 Array platform, and consisted of 27 and 49 matched diagnosisrelapsed ALL samples respectively.

\section{Individual microarray data analysis}

To identify differentially expressed genes in each individual dataset, the limma package which employs a linear modeling approach was used. The raw CEL files was normalized using Robust Multichip Averaging (RMA) implemented in the Affy package, returning $\log 2$ transformed intensities [19]. The normalized datasets were then subjected to limma to compute differentially expressed genes. Genes significantly dysregulated in relapsed ALL as compared to matched data at diagnosis were defined by a $p$-value $<0.05$, and $\log 2$ fold change of $>1$ (upregulated genes) or $<-1$ (downregulated genes). The results of the linear modelling on each dataset and meta-analysis using RankProd method were then compared.

\section{Meta-analysis of multiple microarray datasets}

Meta-analysis was performed on the three datasets using the RankProd package [14] to identify the upregulated and downregulated genes between relapsed ALL and 
matched samples at diagnosis. Initially, the raw CEL files were normalized using RMA implemented in the Affy package, returning log 2 transformed intensities [19]. The normalized datasets were then merged using inSilicoMerging package, and the batch effects was adjusted using method COMBAT [20]. To identify top differentially expressed probesets, the RPadvance function within the RankProd package was used [14]. False discovery rates (pfp) of differential expression were determined using 1000 permutations. The list of upregulated or downregulated probes was identified based on false discovery rate (pfp <0.01) and fold change value $(\mathrm{FC}>1$, upregulated; $\mathrm{FC}<1$, downregulated). Probes that mapped to multiple genes were discarded to avoid misinterpretation of the results and to increase the specificity.

\section{Gene enrichment analysis}

Significantly upregulated $(\mathrm{FC}>1$, pfp $<0.01)$ and downregulated genes $(\mathrm{FC}<1, \mathrm{pfp}<0.01)$ identified by RankProd were subjected for gene enrichment analysis using the Database for Annotation, Visualization, and Integrated Discovery (http://david.abcc.ncifcrf.gov/) [21] to identify over-represented functional classes of genes. STRING [22] was used to identify the protein-protein interaction network on selected clustered genes.

\section{Results}

\section{Individual microarray data analysis of differentially} expressed probes

Differentially expressed genes were identified between relapsed and diagnosed ALL in each study using the limma method which employed the t-test statistical algorithm, and the overlapped genes were examined. As depicted in Fig. 1, based on the cutoff $p$-value $<0.05$ and $\log \mathrm{FC}>1$, we identified 3 probes which were upregulated in GSE3910, 1 probe in GSE18497, and 23 probes in GSE28460. Of these probes, only 2 probes, i.e. 202018_s_at which encodes for LTF, and 202917_s_at which encodes for $S 100 A 8$ were found consistently upregulated in $2 / 3$ datasets. In the downregulation profile ( $p$-value $<0.05$ and $\log \mathrm{FC}<-1$ ), no overlapped candidate probe was found. There were 5 probes uniquely downregulated in GSE3910, whereas 1 probe was downregulated in GSE28460 whereas no probe was found significantly downregulated in GSE18497. The genes' list was as summarized in Additional file 1: Table S1.

\section{Meta-analysis of differentially expressed probes}

To overcome the limitation of small sample sizes in individual study, we then performed meta-analysis on these 3 datasets using RankProd approach. A total of 108 matched diagnosis-relapse ALL samples were pooled together to identify differentially expressed genes implicated in relapsed ALL. The significance of differential gene-expression was calculated based on percentage of false positive predictions (pfp). After removal of probes that mapped to multiple genes or unannotated genes, based on 1000 permutations and a cut-off of false discovery rate at $<0.01$, of the 27,000 probes examined, 1795 probes (corresponding to 1527 genes) were found to be upregulated in relapsed ALL (FC > 1), whilst 1493 probes (corresponding to 1214 genes) were downregulated $(\mathrm{FC}<1)$. The top 20 ranked upregulated and downregulated probes are as listed in Tables 1 and 2 respectively, whilst the list of dysregulated probes are as summarized in Additional file 1: Table S2.

Interestingly, in agreement with the linear modeling approach that identified the upregulation of $5100 A 8$ in relapsed ALL (2/3 microarray datasets, Fig. 1), the metaanalysis also detected this candidate probe as the most significantly upregulated target (Table 1). Therefore, S100A8 appeared to be an attractive and promising
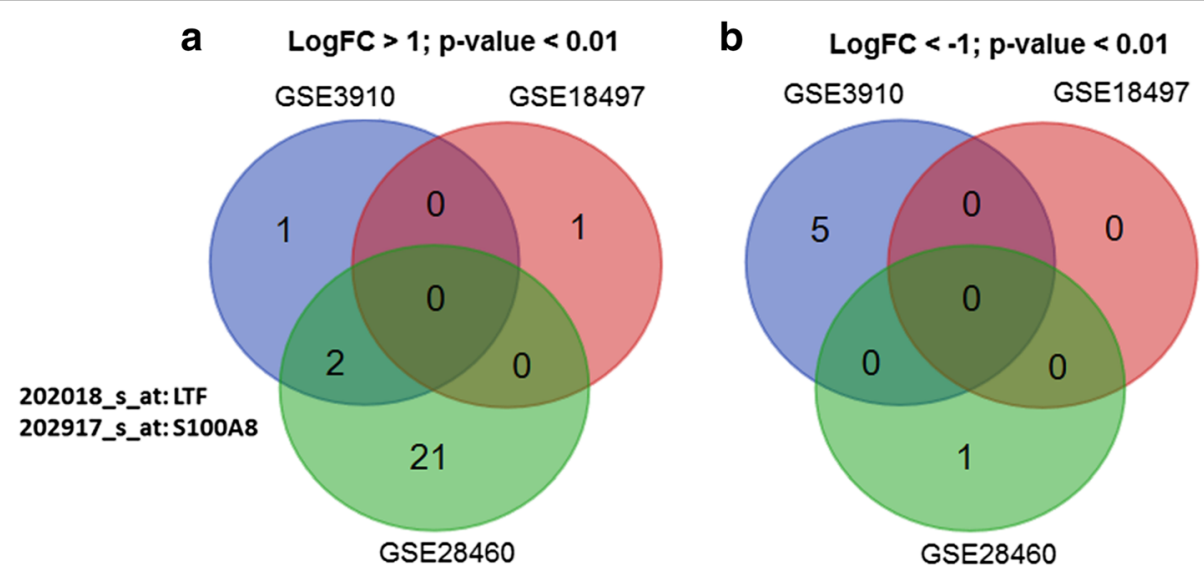

Fig. 1 Venn diagram of differentially expressed probes identified from each individual microarray dataset using limma approach. a Upregulated probes ( $p$-value $<0.01, \log F C>1$ ); $\mathbf{b}$ Downregulated probes ( $p$-value $<0.01, \log F C<-1$ ). Only 2 probes which encode for LTF and S100A8 were found concordantly upregulated in $2 / 3$ studies 
Table 1 The top 20 most significantly upregulated probes identified by RankProd in relapsed childhood ALL (pfp $<0.01$; FC > 1), 1000 permutation

\begin{tabular}{llcll}
\hline Probe & Gene & FC:(class1/class2) & pfp & p.value \\
\hline 202917_s_at & S100A8 & 1.8713 & 0 & 0 \\
203949_at & MPO & 2.0051 & 0 & 0 \\
201427_s_at & SEPP1 & 1.6536 & 0 & 0 \\
213975_s_at & LYZ & 1.6129 & 0 & 0 \\
205000_at & DDX3Y & 1.1483 & 0 & 0 \\
204971_at & CSTA & 1.757 & 0 & 0 \\
209160_at & AKR1C3 & 1.6693 & 0 & 0 \\
209170_s_at & GPM6B & 1.3387 & 0 & 0 \\
204409_s_at & EIF1AY & 1.2661 & 0 & 0 \\
201291_s_at & TOP2A & 1.8054 & 0 & 0 \\
204304_s_at & PROM1 & 1.1579 & 0 & 0 \\
201669_s_at & MARCKS & 1.4776 & 0 & 0 \\
202018_s_at & LTF & 1.6698 & 0 & 0 \\
211657_at & CEACAM6 & 1.3632 & 0 & 0 \\
212077_at & CALD1 & 1.5944 & 0 & 0 \\
221731_x_at & VCAN & 1.3855 & 0 & 0 \\
214039_s_at & LAPTM4B & 1.1776 & 0 & 0 \\
204620_s_at & VCAN & 1.434 & 0 & 0 \\
200665_s_at & SPARC & 1.4726 & 0 & 0 \\
209687_at & CXCL12 & 1.7029 & 0 & 0 \\
\hline FC fold change & S 1 reprent & & 0 \\
\hline
\end{tabular}

FC fold change, class 1 represent relapsed ALL, class 2 diagnosed ALL

biomarker and therapeutic target for relapsed B-ALL that warrants further validation.

As shown in Fig. 2, hierarchical clustering on top 100 dysregulated probes of relapsed and diagnosed childhood B-ALL demonstrated that both groups are not clustered uniquely and were mixed together. This profile indicated that the expression profiles of these 2 samples groups were highly similar.

\section{Functional and pathway analysis}

The significantly dysregulated genes were then annotated using DAVID (Additional file 1: Table S3). As depicted in Figs. 3 and 4, based on gene ontology biological process annotation, the 1527 upregulated genes were most enriched in cell cycle processes (enrichment score $=15.3$ ), whilst the 1214 downregulated genes were enriched in transcription regulation (enrichment score = 12.6). Notably, a total of 161 upregulated genes were cell cycle regulators, and many of them (e.g. kinesins, $C D K s$ ) have been reported to be implicated in leukemia pathogenesis. Of the top 100 significantly upregulated probes, 14 of them (PBK, ASPM, AURKA, BUB1B, BIRC5, CDK1, CEP55, CCNB2, DLGAP5, KIF11, KIF15, NCAP5, GOS2, TTK) encode for cell cycle regulators and are inter-related via protein-protein interaction network
Table 2 The top 20 most significantly downregulated probes identified by RankProd in relapsed childhood ALL (pfp $<0.01$; $\mathrm{FC}<1)$, 1000 permutation

\begin{tabular}{llcll}
\hline Probe & Gene & FC:(class1/class2) & pfp & p.value \\
\hline 209480_at & HLA-DQB1 & 0.8503 & 0 & 0 \\
219737_s_at & PCDH9 & 0.5924 & 0 & 0 \\
210432_s_at & SCN3A & 0.6362 & 0 & 0 \\
203038_at & PTPRK & 0.8517 & 0 & 0 \\
206637_at & P2RY14 & 0.7417 & 0 & 0 \\
204897_at & PTGER4 & 0.6231 & 0 & 0 \\
221728_x_at & XIST & 0.9313 & 0 & 0 \\
212592_at & IGJ & 0.7981 & 0 & 0 \\
221841_s_at & KLF4 & 0.6573 & 0 & 0 \\
203910_at & ARHGAP29 & 0.8594 & 0 & 0 \\
206864_s_at & HRK & 0.6284 & 0 & 0 \\
210448_s_at & P2RX5 & 0.6183 & 0 & 0 \\
214218_s_at & XIST & 0.9554 & 0 & 0 \\
201005_at & CD9 & 0.7092 & 0 & 0 \\
210517_s_at & AKAP12 & 0.8163 & 0 & 0 \\
205081_at & CRIP1 & 0.605 & 0 & 0 \\
204439_at & IFI44L & 0.7068 & 0 & 0 \\
205289_at & BMP2 & 0.7267 & 0 & 0 \\
\hline FC fold change, cass1 & & 0 & \\
\hline
\end{tabular}

FC fold change, class 1 represent relapsed ALL, class 2 diagnosed ALL

(String network, Fig. 5). Of these candidate genes, CDK1, AURKA, and survivin (BIRC5) are the most attractive candidates, whereby numerous inhibitors under development have entered into either phase I/II clinical trials.

\section{Discussion}

In the past decades, microarray has been used widely to investigate differentially expressed genes and dysregulated pathways underlying cancer pathogenesis. Numerous microarray gene expression studies on pediatric ALL have been performed, with few focused on understanding the biological mechanisms underlying relapsed ALL using matched diagnosis-relapsed samples. Also, each published dataset was relatively small $(n<50)$ and the concordance of these studies is rather low based on the publication findings [7-9] or even with the re-analysis on individual dataset using the limma method (Fig. 1; Additional file 1: Table S1). The discrepancies could be attributed to the small size in each single dataset which is underpowered to identify reliable candidates of interest. Hence, meta-analysis which merges all qualified datasets into a single analysis using a more robust statistical method is preferable to yield more meaningful set of differentially expressed genes and to provide new insights into the biological mechanisms. Meta-analysis on multiple microarray datasets of various diseases has 


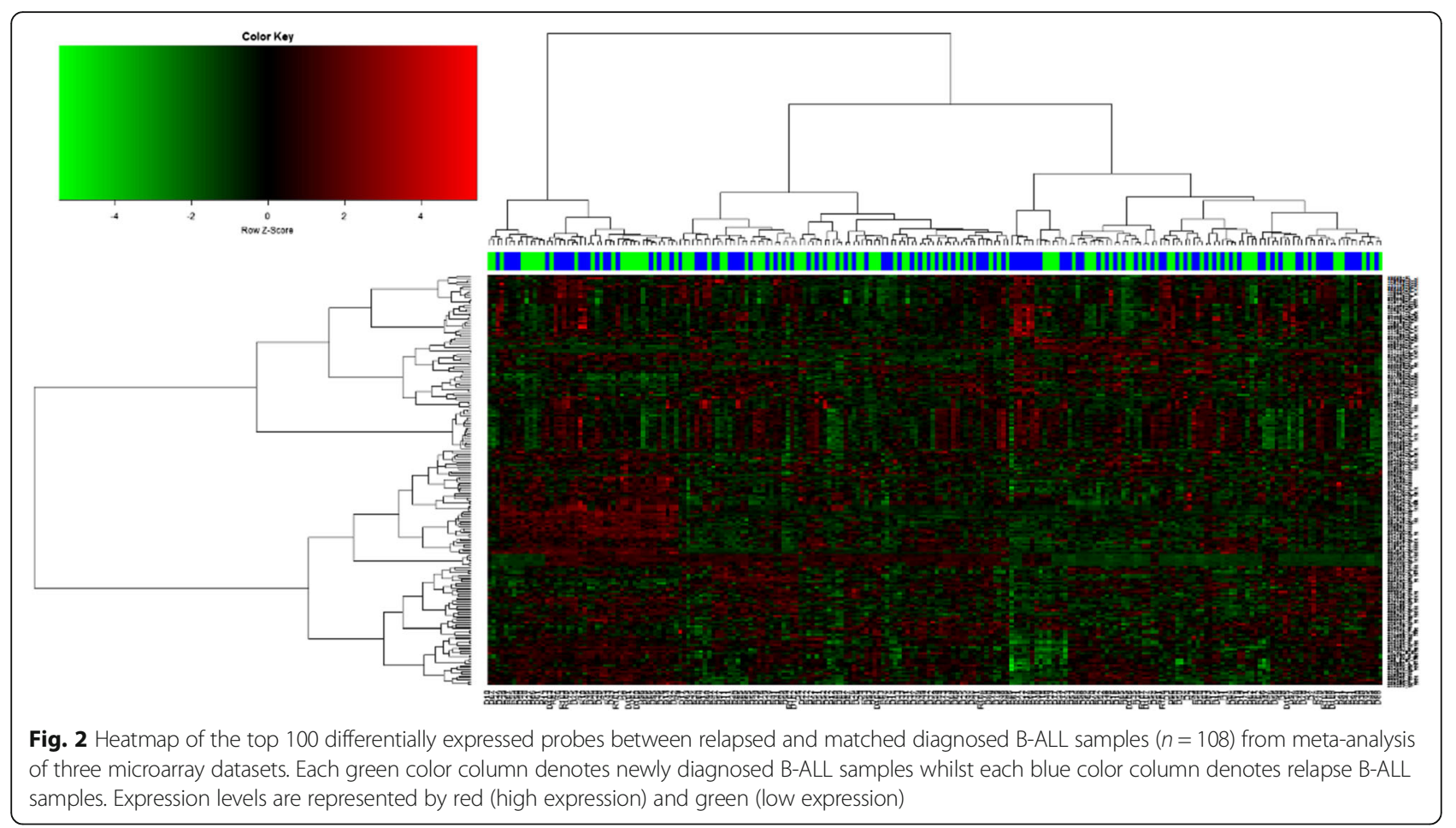

yielded reliable candidates of interest by increasing the statistical power and generalizability [11-13].

Our meta-analysis demonstrated that S100A8 was the top gene upregulated in relapsed ALL as compared to matched diagnosis. S100A8 is a member of the S100 multigene family of cytoplasmic EF-hand Ca2 + -binding proteins [23] and was found overexpressed in various cancer types, and is involved in regulating cell proliferation, metastasis and apoptosis [23-27]. In hematological cancers, S100A8 has been reported to be overexpressed in childhood AML and associated with a worse prognosis [28, 29]. It may be involved in mediating chemoresistance by upregulating autophagy in leukemia cells through promoting the formation of BECN1-PI3KC3 complex [30]. Also, $S 100 A 8$ was found overexpressed in the more aggressive ALL subtype, infant B-ALL, as compared to non-infant B-
ALL [31], and mediated prednisolone-resistant in MLLrearranged infant ALL [32]. Preclinical study has demonstrated S100A8 promoted cell growth of murine B-cell leukemia (BJAB) and human T-cell leukemia (Jurkat) lines [33]. Numerous studies have shown inhibition of S100A8 as a viable treatment strategy for cancers, including leukemia [28, 34-37]. For instance, inhibition of S100A8 has shown increased drug sensitivity and apoptosis of leukemic cells [28]. Given that S100A8 acts as an upstream target of EGFR signaling [38], anti-EGFR therapies, including midostaurin, enzastaurin and gefitinib has been proposed as potential therapy for kidney cancer cells which overexpressed S100A8 [35]. Moreover, increased expression of S100A8 mediated the activation of MAPK and NF$\mathrm{\kappa B}$ pathways, and treatment with p38 MAPK inhibitor SB203580 and the NF-kB inhibitor Bay 11-7082 effectively

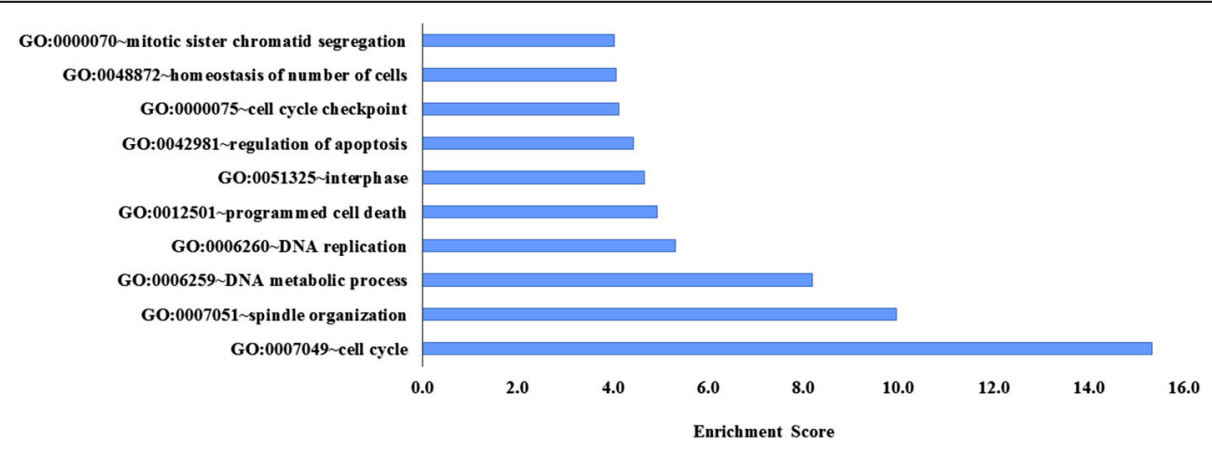

Fig. 3 The ten most significant biological processes associated with genes upregulated in relapsed childhood B-ALL 


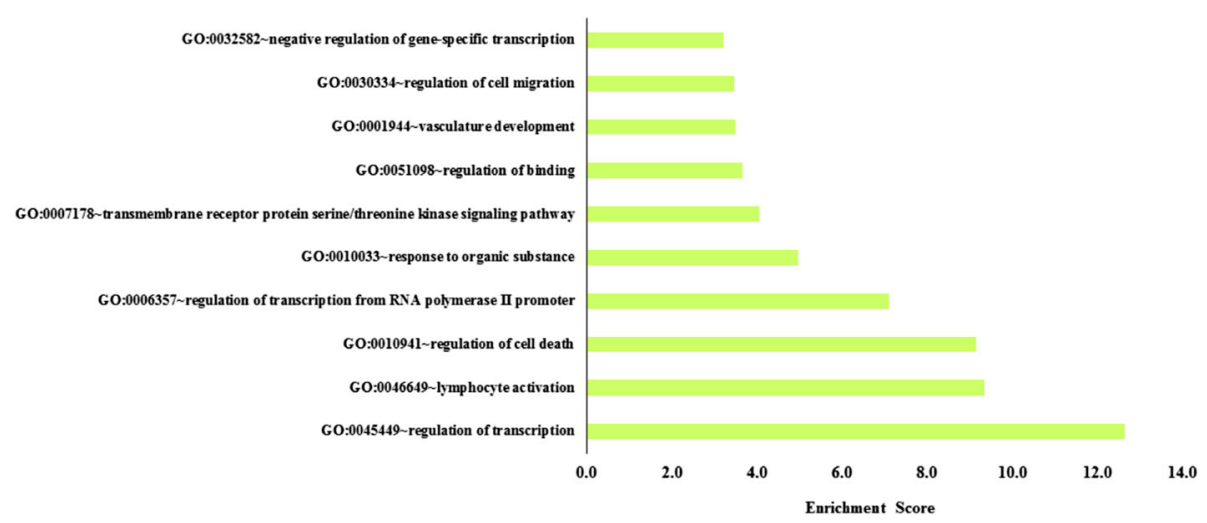

Fig. 4 The ten most significant biological processes associated with genes downregulated in relapsed childhood B-ALL

abolished migration and invasion of cancer cells [39]. Other than conferring selective sensitivity to drugs which target mediators of S100A8, the knockdown of S100A8 expression with siRNA or shRNA also showed reduced invasinesss and migration of cancer cells [28, 34, 36, 37]. Taken together, S100A8 is an ideal target for relapsed ALL therapy, and warrants further investigation.

$M P O$ appeared as the second top ranked upregulated genes, with a fold change $>2$. MPO has been long considered as the hallmark marker for AML cells by the French-American-British and WHO classifications, and has been used clinically to distinguish between AML and ALL. However, several studies reported MPO also being expressed in B-ALL cells, and associated with poorer prognosis [40-43]. For instance, infant B-ALL, a subtype which associated with poorer prognosis was shown to have overexpressed MPO, with an incidence rate of $40-60 \%[42,44]$. Also, B-ALL patients who presented with MPO-positive showed higher incidence of relapse [45], and reduced long-term survival [46]. Our data therefore suggested that MPO may serve as strong indicator for relapse in B-ALL patients. Moreover, silencing of MPO has been shown to effectively induce apoptosis in ovarian cancer cell lines by increasing caspase- 3 activity [47]. Inhibition of MPO-overexpressed cells is therefore of clinical interest.

To date, development of cell cycle inhibitors for cancer therapy is actively ongoing. The most attractive inhibitors are those that target cell cyclin dependent kinases (e.g. $C D K 1$ ) and aurora kinases (e.g. AURKA, AURKB), which are abundantly expressed in various cancer types. Our meta-analysis and several earlier studies have demonstrated

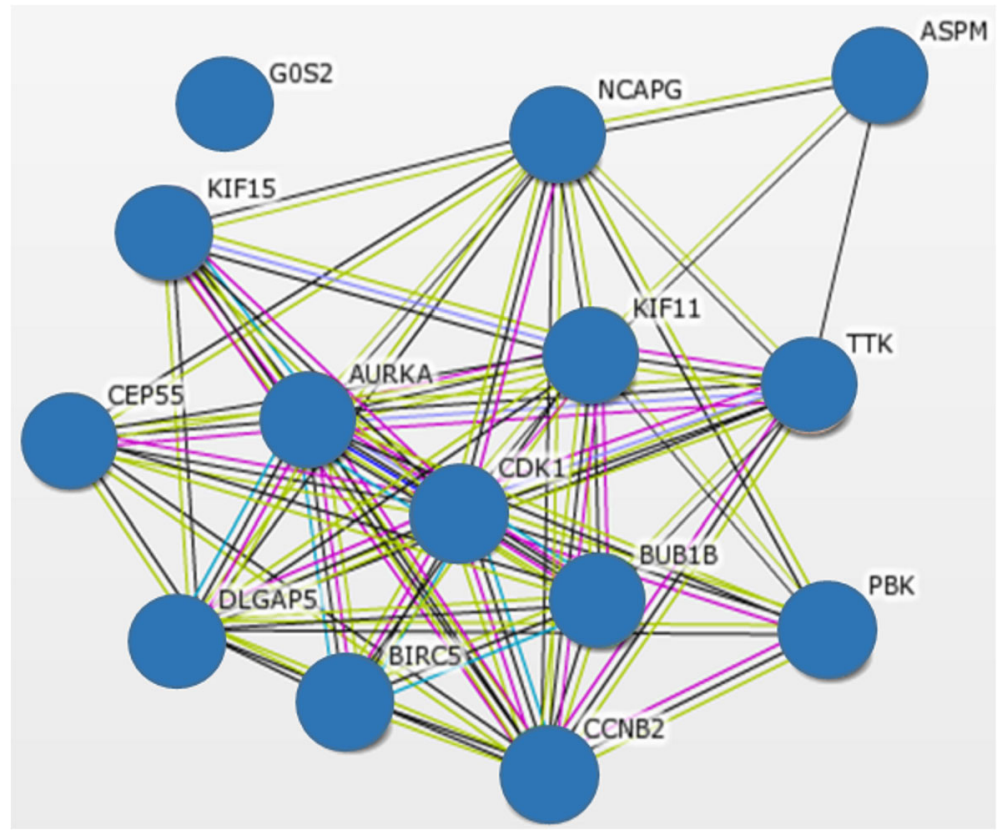

Fig. 5 Protein-protein interaction network of cell cycle genes identified in top 100 upregulated probes in relapsed childhood B-ALL 
that overexpression of cell cycle proteins was prominent and was among the key genetic changes underpinning progression of relapsed childhood B-ALL [7-9]. From the top 100 upregulated genes list, 14 of them are cell cycle regulators and are found to be interactive with each other (Fig. 5). Of those candidates, CDK1 appeared as a key target. To date, numerous CDK inhibitors have entered into clinical trials (https://clinicaltrials.gov), and have shown promising clinical response in leukemia patients. For instance, AML patients treated with a combination of flavopiridol and two chemotherapeutic agents, cytarabine and mitoxantrone, showed a complete remission rate of $75 \%$ [48], as compared to $40-50 \%$ with regimens using only conventional chemotherapy $[49,50]$. Also, Dinaciclib, a novel inhibitor of CDKs 1, 2, 5, and 9, has been shown to be effective in CLL patients and induced lesser myelosuppression [51]. Recently, the approval by FDA on the use of a CDK inhibitor, palbociclib, in combination with letrozole to treat advanced estrogen positive, HER2 negative breast cancer has strengthen the usefulness of CDK inhibitors as new class of anti-cancer therapies [52]. In pediatric ALL, incorporation of CDK inhibitors into standard treatment regimens is yet to be investigated, and it is believed that clinical trials of CDK inhibitors on relapsed childhood B-ALL may be justifiable options to improve patients' survival rate.

Another candidate of cell cycle regulators, AURKA, was also found in the top 100 upregulated genes list in our meta-analysis. AURKA is one of the three aurora kinases (AURKA, AURKB, and AURKC) which play essential roles in cell proliferation, regulating cell cycle transit from G2, formation of the mitotic spindle, centrosome maturation and separation, and cytokinesis [53-55]. Overexpression of AURKA has been documented in solid tumors and hematological cancers [56-60]. Higher levels of AURKA expression were correlated with higher tumor grade, and poorer prognosis [61-64]. Furthermore, overexpression of AURKA mediated resistance to gefitinib, taxol and cisplatin in cancer cells [65-67]. Inhibition of AURKA has been shown to increase cisplatin-induced apoptosis [66]. It is noteworthy that more than 30 AURKA inhibitors have been tested in clinical studies [68]. For relapsed and refractory AML patients, an early phase I/II clinical trial on AURKA inhibitor, MLN8237, has shown 13\% complete response rate, $11 \%$ partial response rate, and $49 \%$ stable disease [69]. Given that the levels of AURKA expression was elevated in relapsed pediatric B-ALL, it would be worthwhile to investigate the efficacy of AURKA inhibitor in this group of patients.

Earlier studies have identified survivin overexpression as a strong risk factor for relapse in childhood B-ALL [70]. Independent microarray studies using other analysis pipelines have reported survivin as a key gene upregulated in relapsed ALL $[7,8]$. Our analysis has strengthened the fact that targeting survivin is a promising therapeutic strategy, and warrants further investigation. Survivin is part of the AuroraB-survivin-INCENP-Borealin/Dasra B complex, an essential component for cell-cycle progression and cytokinesis [71]. It plays an important role in regulating cell proliferation and apoptosis suppression. Survivin was also found to be overexpressed in adult AML and T-cell leukemia [72, 73] as well as childhood AML [74-76], and associated with poorer survival outcome. Upregulation of survivin is mediated by multiple signaling pathways and by the tumor microenvironment including PI3K, MAPK, STAT3, Wnt/-catenin, hypoxia, angiogenesis, and NF-k $\beta$ signaling pathways $[53,76-80]$, hence may serve as an important target for leukemia therapy. Survivin also mediates resistance to chemotherapeutic agents, including vincristine, cisplatin, and tamoxifen in tumor cells [81-83]. Down-regulation of survivin via antisense oligonucleotides was shown to enhance sensitivity of various cancer cell types to cytotoxic agents such as TRAIL [84], cisplatin [85], taxol [86], imatinib [87], as well as to cytotoxicity induced by radiation therapy [88]. To date, several clinical trials on survivin employing different approaches including antisense oligonucleotides, small molecule inhibitors and immunotherapy are in progress ([89-92], http:// www.clinicaltrials.gov), and is offered as an treatment option for terminally ill relapsed B-ALL patients within in the context of clinical trial.

Taken together, our meta-analysis on paired diagnosis-relapsed B-ALL has strengthened the evidence for the roles of cell cycle dysregulation as the key component of genetic alterations underpinning disease progression, and can be considered as the promising pathway for new therapeutic intervention. The efficacy of targeted cell cycle therapies to treat relapsed pediatric B-ALL patients shall be further evaluated in the context of clinical trials.

\section{Conclusion}

In summary, our analysis identified $S 100 A 8$ as the top most promising biomarker and therapeutic candidate for relapsed childhood B-ALL. Dysregulation of the cell cycle is the key genetic event implicated in relapsed ALL, and an in-depth investigation of the efficacy of cell cycle inhibitors (e.g. CDK inhibitors, and aurora kinases inhibitors) in eliminating relapsed leukemic cells is warranted to improve patients' survival rate.

\section{Additional file}

Additional file 1: Table S1. List of significantly differentially expressed probes identified in GSE3910, GSE18497, and GSE28460 analyzed by limma approach. Table S2. List of significantly differentially expressed probes identified in the meta-analysis of three microarray datasets (GSE3910, GSE18497, GSE28460) using RankProd approach. Table S3. Gene set enrichment analysis for the significant upregulated and downregulated genes analzyed by DAVID. (XLSX 248 kb) 


\section{Abbreviations}

ALL: Acute lymphoblastic leukemia; AURK: Aurora kinase; CDK: Cyclin dependent kinase; FC: Fold change; logFC: Log2 fold change; pfp: Probability of false prediction; RMA: Robust Multichip Averaging

\section{Acknowledgements}

Not applicable.

\section{Funding}

This work was supported by Genomic Unit PPUKM-UMBI fund. The funding body did not involve in the design of the study and in data collection, analysis, and interpretation and in writing the manuscript.

\section{Availability of data and materials}

All relevant data are within the paper. The microarray datasets used in this study are publicly available in Gene Expression Omnibus database GEO and ArrayExpress databases.

\section{Authors' contributions}

CYP involved in the study design, data analysis and manuscript drafting. RJ and HA involved in the study and critical evaluation of the manuscript. All authors read and approved the final manuscript.

\section{Authors' information}

Not applicable.

\section{Competing interests}

The authors declare that they have no competing interests.

\section{Consent for publication}

Not applicable.

Ethics approval and consent to participate

Not applicable.

Received: 24 August 2016 Accepted: 1 February 2017

Published online: 10 February 2017

\section{References}

1. Reismüller B, Attarbaschi A, Peters C, Dworzak MN, Pötschger U, Urban C, Fink FM, Meister B, Schmitt K, Dieckmann K, et al. Long-term outcome of initially homogenously treated and relapsed childhood acute lymphoblastic leukaemia in Austria-a population-based report of the Austrian BerlinFrankfurt-Münster (BFM) Study Group. Br J Haematol. 2009;144(4):559-70.

2. Roy A, Cargill A, Love S, Moorman AV, Stoneham S, Lim A, Darbyshire PJ, Lancaster D, Hann I, Eden T, et al. Outcome after first relapse in childhood acute lymphoblastic leukaemia - lessons from the United Kingdom R2 trial. Br J Haematol. 2005;130(1):67-75.

3. Hunger SP, Lu X, Devidas M, Camitta BM, Gaynon PS, Winick NJ, Reaman $\mathrm{GH}$, Carroll WL. Improved survival for children and adolescents with acute lymphoblastic leukemia between 1990 and 2005: a report from the children's oncology group. J Clin Oncol. 2012;30(14):1663-9.

4. Parker C, Waters R, Leighton C, Hancock J, Sutton R, Moorman AV, Ancliff P, Morgan M, Masurekar A, Goulden N, et al. Effect of mitoxantrone on outcome of children with first relapse of acute lymphoblastic leukaemia (ALL R3): an open-label randomised trial. Lancet. 2010;376(9757):2009-17.

5. Tallen G, Ratei R, Mann G, Kaspers G, Niggli F, Karachunsky A, Ebell W, Escherich G, Schrappe M, Klingebiel T, et al. Long-term outcome in children with relapsed acute lymphoblastic leukemia after time-point and site-ofrelapse stratification and intensified short-course multidrug chemotherapy: results of trial ALL-REZ BFM 90. J Clin Oncol. 2010;28(14):2339-47.

6. Einsiedel $H G$, von Stackelberg A, Hartmann R, Fengler R, Schrappe M, JankaSchaub G, Mann G, Hählen K, Göbel U, Klingebiel T, et al. Long-term outcome in children with relapsed ALL by risk-stratified salvage therapy: results of trial acute lymphoblastic leukemia-relapse study of the BerlinFrankfurt-Münster Group 87. J Clin Oncol. 2005;23(31):7942-50.

7. Hogan LE, Meyer JA, Yang J, Wang J, Wong N, Yang W, Condos G, Hunger $S P$, Raetz E, Saffery $R$, et al. Integrated genomic analysis of relapsed childhood acute lymphoblastic leukemia reveals therapeutic strategies. Blood. 2011;118(19):5218-26.
8. Bhojwani D, Kang H, Moskowitz NP, Min DJ, Lee H, Potter JW, Davidson G, Willman CL, Borowitz MJ, Belitskaya-Levy I, et al. Biologic pathways associated with relapse in childhood acute lymphoblastic leukemia: a Children's Oncology Group study. Blood. 2006;108(2):711-7.

9. Staal FJ, van der Burg M, Wessels LF, Barendregt BH, Baert MR, van den Burg CM, van Huffel C, Langerak AW, van der Velden VH, Reinders MJ, et al. DNA microarrays for comparison of gene expression profiles between diagnosis and relapse in precursor-B acute lymphoblastic leukemia: choice of technique and purification influence the identification of potential diagnostic markers. Leukemia. 2003;17(7):1324-32.

10. Beesley AH, Cummings AJ, Freitas JR, Hoffmann K, Firth MJ, Ford J, de Klerk NH, Kees UR. The gene expression signature of relapse in paediatric acute lymphoblastic leukaemia: implications for mechanisms of therapy failure. Br J Haematol. 2005;131(4):447-56.

11. Goonesekere NC, Wang X, Ludwig L, Guda C. A meta analysis of pancreatic microarray datasets yields new targets as cancer genes and biomarkers. PLoS One. 2014;9(4):e93046.

12. Botling J, Edlund $K$, Lohr M, Hellwig B, Holmberg L, Lambe M, Berglund A, Ekman S, Bergqvist M, Pontén F, et al. Biomarker discovery in non-small cell lung cancer: integrating gene expression profiling, meta-analysis, and tissue microarray validation. Clin Cancer Res. 2013; 19(1):194-204.

13. Chan SK, Griffith OL, Tai IT, Jones SJ. Meta-analysis of colorectal cancer gene expression profiling studies identifies consistently reported candidate biomarkers. Cancer Epidemiol Biomarkers Prev. 2008;17(3):543-52.

14. Breitling R, Armengaud P, Amtmann A, Herzyk P. Rank products: a simple, yet powerful, new method to detect differentially regulated genes in replicated microarray experiments. FEBS Lett. 2004;573(1-3):83-92.

15. Hong F, Breitling R, McEntee CW, Wittner BS, Nemhauser JL, Chory J. RankProd: a bioconductor package for detecting differentially expressed genes in meta-analysis. Bioinformatics. 2006;22(22):2825-7.

16. Choi $H$, Shen $R$, Chinnaiyan AM, Ghosh D. A latent variable approach for meta-analysis of gene expression data from multiple microarray experiments. BMC Bioinformatics. 2007;8:364.

17. Choi JK, Yu U, Kim S, Yoo OJ. Combining multiple microarray studies and modeling interstudy variation. Bioinformatics. 2003;19 Suppl 1:i84-90.

18. Zhang Z, Fenstermacher D. An Introduction to MAMA (Meta-Analysis of MicroArray data) System. Conf Proc IEEE Eng Med Biol Soc. 2005;7:7730-3.

19. Irizarry RA, Bolstad BM, Collin F, Cope LM, Hobbs B, Speed TP. Summaries of Affymetrix GeneChip probe level data. Nucleic Acids Res. 2003;31(4):e15.

20. Taminau J, Meganck S, Lazar C, Steenhoff D, Coletta A, Molter C, Duque R, de Schaetzen V, Weiss Solís DY, Bersini H, et al. Unlocking the potential of publicly available microarray data using insilicoDb and inSilicoMerging R/ Bioconductor packages. BMC Bioinformatics. 2012;13:335.

21. Huang DW, Sherman BT, Lempicki RA. Systematic and integrative analysis of large gene lists using DAVID bioinformatics resources. Nat Protoc. 2009;4(1):44-57.

22. Szklarczyk D, Franceschini A, Wyder S, Forslund K, Heller D, HuertaCepas J, Simonovic M, Roth A, Santos A, Tsafou KP, et al. STRING v10: protein-protein interaction networks, integrated over the tree of life. Nucleic Acids Res. 2015;43(Database issue):D447-452.

23. Srikrishna G. S100A8 and S100A9: new insights into their roles in malignancy. J Innate Immun. 2012:4(1):31-40.

24. Mirza Z, Schulten HJ, Farsi HM, Al-Maghrabi JA, Gari MA, Chaudhary AG, Abuzenadah AM, Al-Qahtani MH, Karim S. Impact of S100A8 expression on kidney cancer progression and molecular docking studies for kidney cancer therapeutics. Anticancer Res. 2014;34(4):1873-84.

25. Duan L, Wu R, Ye L, Wang H, Yang X, Zhang Y, Chen X, Zuo G, Weng Y, Luo J, et al. S100A8 and S100A9 are associated with colorectal carcinoma progression and contribute to colorectal carcinoma cell survival and migration via Wnt/ $\beta$ catenin pathway. PLoS One. 2013;8(4):e62092.

26. Yao R, Lopez-Beltran A, Maclennan GT, Montironi R, Eble JN, Cheng L. Expression of $\mathrm{S} 100$ protein family members in the pathogenesis of bladder tumors. Anticancer Res. 2007;27(5A):3051-8.

27. Yong HY, Moon A. Roles of calcium-binding proteins, S100A8 and S100A9, in invasive phenotype of human gastric cancer cells. Arch Pharm Res. 2007; 30(1):75-81.

28. Yang L, Yang M, Zhang $H$, Wang Z, Yu Y, Xie M, Zhao M, Liu L, Cao L. S100A8-targeting siRNA enhances arsenic trioxide-induced myeloid leukemia cell death by down-regulating autophagy. Int J Mol Med. 2012; 29(1):65-72. 
29. Nicolas E, Ramus C, Berthier S, Arlotto M, Bouamrani A, Lefebvre C, Morel F, Garin J, Ifrah N, Berger F, et al. Expression of S100A8 in leukemic cells predicts poor survival in de novo AML patients. Leukemia. 2011;25(1):57-65.

30. Yang M, Zeng P, Kang R, Yu Y, Yang L, Tang D, Cao L. S100A8 contributes to drug resistance by promoting autophagy in leukemia cells. PLoS One. 2014;9(5):e97242.

31. Qazi S, Uckun FM. Gene expression profiles of infant acute lymphoblastic leukaemia and its prognostically distinct subsets. Br J Haematol. 2010; 149(6):865-73.

32. Spijkers-Hagelstein JA, Schneider P, Hulleman E, de Boer J, Williams O, Pieters R, Stam RW. Elevated S100A8/S100A9 expression causes glucocorticoid resistance in MLL-rearranged infant acute lymphoblastic leukemia. Leukemia. 2012;26(6):1255-65.

33. Ghavami S, Kerkhoff C, Chazin WJ, Kadkhoda K, Xiao W, Zuse A, Hashemi M, Eshraghi M, Schulze-Osthoff K, Klonisch T, et al. S100A8/9 induces cell death via a novel, RAGE-independent pathway that involves selective release of Smac/DIABLO and Omi/HtrA2. Biochim Biophys Acta. 2008;1783(2):297-311.

34. Lim SY, Yuzhalin AE, Gordon-Weeks AN, Muschel RJ. Tumor-infiltrating monocytes/macrophages promote tumor invasion and migration by upregulating S100A8 and S100A9 expression in cancer cells. Oncogene. 2016;35(44):5735-45.

35. Mirza Z, Schulten HJ, Farsi HM, Al-Maghrabi JA, Gari MA, Chaudhary AG, Abuzenadah AM, Al-Qahtani MH, Karim S. Molecular interaction of a kinase inhibitor midostaurin with anticancer drug targets, S100A8 and EGFR: transcriptional profiling and molecular docking study for kidney cancer therapeutics. PLoS One. 2015;10(3):e0119765.

36. Yan LL, Huang YJ, Yi X, Yan XM, Cai Y, He Q, Han ZJ. Effects of silencing S100A8 and S100A9 with small interfering RNA on the migration of CNE1 nasopharyngeal carcinoma cells. Oncol Lett. 2015;9(6):2534-40.

37. Moon A, Yong HY, Song Jl, Cukovic D, Salagrama S, Kaplan D, Putt D, Kim H, Dombkowski A, Kim HR. Global gene expression profiling unveils S100A8/A9 as candidate markers in $\mathrm{H}$-ras-mediated human breast epithelial cell invasion. Mol Cancer Res. 2008;6(10):1544-53.

38. Heizmann CW, Fritz G, Schäfer BW. S100 proteins: structure, functions and pathology. Front Biosci. 2002;7:d1356-1368.

39. Kwon CH, Moon HJ, Park HJ, Choi JH, Park DY. S100A8 and S100A9 promotes invasion and migration through p38 mitogen-activated protein kinase-dependent NF-kB activation in gastric cancer cells. Mol Cells. 2013; 35(3):226-34.

40. Rytting ME, Kantarjian H, Albitar M. Acute lymphoblastic leukemia with Burkitt-like morphologic features and high myeloperoxidase activity. Am J Clin Pathol. 2009;132(2):182-5. quiz 306.

41. Serrano J, Lo Coco F, Sprovieri T, Elia L, Vitale A, Gregorj C, Tafuri A, Sánchez J, Román J, Torres A, et al. Myeloperoxidase gene expression in non-infant pro-B acute lymphoblastic leukaemia with or without ALL1/AF4 transcript. Br J Haematol. 2000;111(4):1065-70.

42. Austin GE, Alvarado CS, Austin ED, Hakami N, Zhao WG, Chauvenet A, Borowitz MJ, Carroll AJ. Prevalence of myeloperoxidase gene expression in infant acute lymphocytic leukemia. Am J Clin Pathol. 1998;110(5):575-81.

43. Wright $\mathrm{S}$, Chucrallah A, Chong YY, Kantarjian H, Keating M, Albitar M. Acute lymphoblastic leukemia with myeloperoxidase activity. Am J Hematol. 1996; 51(2):147-51.

44. Zhou M, Findley HW, Zaki SR, Little F, Coffield LM, Ragab AH. Expression of myeloperoxidase mRNA by leukemic cells from childhood acute lymphoblastic leukemia. Leukemia. 1993;7(8):1180-3.

45. Serrano J, Román J, Jiménez A, Castillejo JA, Navarro JA, Sánchez J, GarcíaCastellanos JM, Martín C, Maldonado J, Torres A. Genetic, phenotypic and clinical features of acute lymphoblastic leukemias expressing myeloperoxidase mRNA detected by RT-PCR. Leukemia. 1999;13(2):175-80.

46. Preti A, Kantarjian HM, Estey E, Huh Y, Keating M, Pierce S, Hirsch-Ginsberg C, Yee G, Stass SA. Characteristics and outcome of patients with acute lymphocytic leukemia and myeloperoxidase-positive blasts by electron microscopy. Hematol Pathol. 1994;8(4):155-67.

47. Saed GM, Ali-Fehmi R, Jiang ZL, Fletcher NM, Diamond MP, Abu-Soud HM, Munkarah AR. Myeloperoxidase serves as a redox switch that regulates apoptosis in epithelial ovarian cancer. Gynecol Oncol. 2010;116(2):276-81.

48. Karp JE, Smith BD, Levis MJ, Gore SD, Greer J, Hattenburg C, Briel J, Jones RJ, Wright JJ, Colevas AD. Sequential flavopiridol, cytosine arabinoside, and mitoxantrone: a phase II trial in adults with poor-risk acute myelogenous leukemia. Clin Cancer Res. 2007;13(15 Pt 1):4467-73.
49. Bolaños-Meade J, Karp JE, Guo C, Sarkodee-Adoo CB, Rapoport AP, Tidwell ML, Buddharaju LN, Chen $\Pi$. Timed sequential therapy of acute myelogenous leukemia in adults: a phase II study of retinoids in combination with the sequential administration of cytosine arabinoside, idarubicin and etoposide. Leuk Res. 2003;27(4):313-21.

50. Geller RB, Burke PJ, Karp JE, Humphrey RL, Braine HG, Tucker RW, Fox MG, Zahurak M, Morrell L, Hall KL. A two-step timed sequential treatment for acute myelocytic leukemia. Blood. 1989;74(5):1499-506.

51. Flynn J, Jones J, Johnson AJ, Andritsos L, Maddocks K, Jaglowski S, Hessler J, Grever MR, Im E, Zhou H, et al. Dinaciclib is a novel cyclin-dependent kinase inhibitor with significant clinical activity in relapsed and refractory chronic lymphocytic leukemia. Leukemia. 2015;29(7):1524-9.

52. Lu J. Palbociclib: a first-in-class CDK4/CDK6 inhibitor for the treatment of hormone-receptor positive advanced breast cancer. J Hematol Oncol. 2015;8:98

53. Andrews PD. Aurora kinases: shining lights on the therapeutic horizon? Oncogene. 2005;24(32):5005-15.

54. Marumoto T, Zhang D, Saya H. Aurora-A - a guardian of poles. Nat Rev Cancer. 2005;5(1):42-50.

55. Andrews PD, Knatko E, Moore WJ, Swedlow JR. Mitotic mechanics: the auroras come into view. Curr Opin Cell Biol. 2003;15(6):672-83.

56. Huang XF, Luo SK, Xu J, Li J, Xu DR, Wang LH, Yan M, Wang XR, Wan $X B$, Zheng FM, et al. Aurora kinase inhibitory $V X-680$ increases Bax/BCl-2 ratio and induces apoptosis in Aurora-A-high acute myeloid leukemia. Blood. 2008;111(5):2854-65.

57. Ikezoe T, Yang J, Nishioka C, Tasaka T, Taniguchi A, Kuwayama Y, Komatsu N, Bandobashi K, Togitani K, Koeffler HP, et al. A novel treatment strategy targeting Aurora kinases in acute myelogenous leukemia. Mol Cancer Ther. 2007;6(6):1851-7.

58. Yang J, Ikezoe T, Nishioka C, Tasaka T, Taniguchi A, Kuwayama Y, Komatsu N, Bandobashi K, Togitani K, Koeffler HP, et al. AZD1152, a novel and selective aurora B kinase inhibitor, induces growth arrest, apoptosis, and sensitization for tubulin depolymerizing agent or topoisomerase II inhibitor in human acute leukemia cells in vitro and in vivo. Blood. 2007; 110(6):2034-40.

59. Fraizer GC, Diaz MF, Lee IL, Grossman HB, Sen S. Aurora-A/STK15/BTAK enhances chromosomal instability in bladder cancer cells. Int J Oncol. 2004; 25(6):1631-9.

60. Gritsko TM, Coppola D, Paciga JE, Yang L, Sun M, Shelley SA, Fiorica JV, Nicosia SV, Cheng JQ. Activation and overexpression of centrosome kinase BTAK/Aurora-A in human ovarian cancer. Clin Cancer Res. 2003;9(4): 1420-6.

61. Yeh CN, Yen CC, Chen YY, Cheng CT, Huang SC, Chang TW, Yao FY, Lin YC, Wen YS, Chiang KC, et al. Identification of aurora kinase $A$ as an unfavorable prognostic factor and potential treatment target for metastatic gastrointestinal stromal tumors. Oncotarget. 2014;5(12):4071-86.

62. Borges KS, Moreno DA, Martinelli CE, Antonini SR, de Castro M, Tucci S, Neder L, Ramalho LN, Seidinger AL, Cardinalli I, et al. Spindle assembly checkpoint gene expression in childhood adrenocortical tumors (ACT): Overexpression of Aurora kinases $A$ and $B$ is associated with a poor prognosis. Pediatr Blood Cancer. 2013;60(11):1809-16.

63. Goos JA, Coupe VM, Diosdado B, Delis-Van Diemen PM, Karga C, Beliën JA, Carvalho B, van den Tol MP, Verheul HM, Geldof AA, et al. Aurora kinase A (AURKA) expression in colorectal cancer liver metastasis is associated with poor prognosis. Br J Cancer. 2013;109(9):2445-52.

64. Xu J, Wu X, Zhou WH, Liu AW, Wu JB, Deng JY, Yue CF, Yang SB, Wang J, Yuan ZY, et al. Aurora-A identifies early recurrence and poor prognosis and promises a potential therapeutic target in triple negative breast cancer. PLoS One. 2013:8(2):e56919.

65. Cirak Y, Furuncuoglu Y, Yapicier O, Aksu A, Cubukcu E. Aurora A overexpression in breast cancer patients induces taxane resistance and results in worse prognosis. J BUON. 2015;20(6):1414-9.

66. Wu CC, Yu CT, Chang GC, Lai JM, Hsu SL. Aurora-A promotes gefitinib resistance via a NF-kB signaling pathway in p53 knockdown lung cancer cells. Biochem Biophys Res Commun. 2011;405(2):168-72.

67. Xu J, Yue CF, Zhou WH, Qian YM, Zhang Y, Wang SW, Liu AW, Liu Q. Aurora-A contributes to cisplatin resistance and lymphatic metastasis in non-small cell lung cancer and predicts poor prognosis. J Transl Med. 2014;12:200.

68. Kollareddy M, Zheleva D, Dzubak P, Brahmkshatriya PS, Lepsik M, Hajduch M. Aurora kinase inhibitors: progress towards the clinic. Invest New Drugs. 2012;30(6):2411-32. 
69. Goldberg SL, Fenaux P, Craig MD, Gyan E, Lister J, Kassis J, Pigneux A, Schiller GJ, Jung J, Jane Leonard E, et al. An exploratory phase 2 study of investigational Aurora A kinase inhibitor alisertib (MLN8237) in acute myelogenous leukemia and myelodysplastic syndromes. Leuk Res Rep. 2014;3(2):58-61.

70. Troeger A, Siepermann M, Escherich G, Meisel R, Willers R, Gudowius S, Moritz T, Laws HJ, Hanenberg H, Goebel U, et al. Survivin and its prognostic significance in pediatric acute B-cell precursor lymphoblastic leukemia. Haematologica. 2007;92(8):1043-50.

71. Honda R, Körner R, Nigg EA. Exploring the functional interactions between Aurora B, INCENP, and survivin in mitosis. Mol Biol Cell. 2003;14(8):3325-41.

72. Nakayama K, Kamihira S. Survivin an important determinant for prognosis in adult T-cell leukemia: a novel biomarker in practical hemato-oncology. Leuk Lymphoma. 2002;43(12):2249-55.

73. Adida C, Haioun C, Gaulard P, Lepage E, Morel P, Briere J, Dombret H, Reyes F, Diebold J, Gisselbrecht C, et al. Prognostic significance of survivin expression in diffuse large B-cell lymphomas. Blood. 2000;96(5):1921-5.

74. Tamm I, Richter S, Oltersdorf D, Creutzig U, Harbott J, Scholz F, Karawajew L, Ludwig WD, Wuchter C. High expression levels of $x$-linked inhibitor of apoptosis protein and survivin correlate with poor overall survival in childhood de novo acute myeloid leukemia. Clin Cancer Res. 2004;10(11):3737-44.

75. Wuchter C, Richter S, Oltersdorf D, Karawajew L, Ludwig WD, Tamm I. Differences in the expression pattern of apoptosis-related molecules between childhood and adult de novo acute myeloid leukemia. Haematologica. 2004;89(3):363-4.

76. Carter BZ, Milella M, Altieri DC, Andreeff M. Cytokine-regulated expression of survivin in myeloid leukemia. Blood. 2001;97(9):2784-90.

77. Yang L, Cao Z, Li F, Post DE, Van Meir EG, Zhong H, Wood WC. Tumorspecific gene expression using the survivin promoter is further increased by hypoxia. Gene Ther. 2004;11(15):1215-23.

78. Mitsiades CS, Mitsiades N, Poulaki V, Schlossman R, Akiyama M, Chauhan D, Hideshima T, Treon SP, Munshi NC, Richardson PG, et al. Activation of NFkappaB and upregulation of intracellular anti-apoptotic proteins via the IGF1/Akt signaling in human multiple myeloma cells: therapeutic implications. Oncogene. 2002;21(37):5673-83.

79. Mahboubi K, Li F, Plescia J, Kirkiles-Smith NC, Mesri M, Du Y, Carroll JM, Elias JA, Altieri DC, Pober JS. Interleukin-11 up-regulates survivin expression in endothelial cells through a signal transducer and activator of transcription-3 pathway. Lab Invest. 2001;81(3):327-34.

80. Papapetropoulos A, Fulton D, Mahboubi K, Kalb RG, O'Connor DS, Li F, Altieri DC, Sessa WC. Angiopoietin-1 inhibits endothelial cell apoptosis via the Akt/survivin pathway. J Biol Chem. 2000;275(13):9102-5.

81. Huang W, Mao Y, Zhan Y, Huang J, Wang X, Luo P, Li LI, Mo D, Liu Q, Xu H, et al. Prognostic implications of survivin and lung resistance protein in advanced non-small cell lung cancer treated with platinum-based chemotherapy. Oncol Lett. 2016;11(1):723-30.

82. Tsubaki M, Takeda T, Ogawa N, Sakamoto K, Shimaoka H, Fujita A, Itoh T, Imano M, Ishizaka T, Satou T, et al. Overexpression of survivin via activation of ERK1/2, Akt, and NF-KB plays a central role in vincristine resistance in multiple myeloma cells. Leuk Res. 2015;39(4):445-52.

83. Moriai R, Tsuji N, Moriai M, Kobayashi D, Watanabe N. Survivin plays as a resistant factor against tamoxifen-induced apoptosis in human breast cancer cells. Breast Cancer Res Treat. 2009;117(2):261-71.

84. Azuhata T, Scott D, Griffith TS, Miller M, Sandler AD. Survivin inhibits apoptosis induced by TRAIL, and the ratio between survivin and TRAIL receptors is predictive of recurrent disease in neuroblastoma. J Pediatr Surg. 2006;41(8):1431-40.

85. Ganesh S, lyer AK, Weiler J, Morrissey DV, Amiji MM. Combination of siRNAdirected gene silencing with cisplatin reverses drug resistance in human non-small cell lung cancer. Mol Ther Nucleic Acids. 2013;2:e110.

86. Li W, Wang X, Lei P, Ye Q, Zhu H, Zhang Y, Shao J, Yang J, Shen G. Antisense RNA of survivin gene inhibits the proliferation of leukemia cells and sensitizes leukemia cell line to taxol-induced apoptosis. J Huazhong Univ Sci Technolog Med Sci. 2008;28(1):1-5.

87. Stella S, Tirrò E, Conte E, Stagno F, Di Raimondo F, Manzella L, Vigneri P. Suppression of survivin induced by a BCR-ABL/JAK2/STAT3 pathway sensitizes imatinib-resistant CML cells to different cytotoxic drugs. Mol Cancer Ther. 2013;12(6):1085-98.

88. Sah NK, Munshi A, Hobbs M, Carter BZ, Andreeff M, Meyn RE. Effect of downregulation of survivin expression on radiosensitivity of human epidermoid carcinoma cells. Int J Radiat Oncol Biol Phys. 2006;66(3):852-9.
89. Clemens MR, Gladkov OA, Gartner E, Vladimirov V, Crown J, Steinberg J, Jie F, Keating A. Phase II, multicenter, open-label, randomized study of YM155 plus docetaxel as first-line treatment in patients with HER2-negative metastatic breast cancer. Breast Cancer Res Treat. 2015;149(1):171-9.

90. Kudchadkar R, Ernst S, Chmielowski B, Redman BG, Steinberg J, Keating A, Jie F, Chen C, Gonzalez R, Weber J. A phase 2, multicenter, open-label study of sepantronium bromide (YM155) plus docetaxel in patients with stage III (unresectable) or stage IV melanoma. Cancer Med. 2015;4(5):643-50.

91. Natale R, Blackhall F, Kowalski D, Ramlau R, Bepler G, Grossi F, Lerchenmüller C, Pinder-Schenck M, Mezger J, Danson S, et al. Evaluation of antitumor activity using change in tumor size of the survivin antisense oligonucleotide LY2181308 in combination with docetaxel for second-line treatment of patients with non-small-cell lung cancer: a randomized open-label phase II study. J Thorac Oncol. 2014;9(11):1704-8.

92. Lennerz V, Gross S, Gallerani E, Sessa C, Mach N, Boehm S, Hess D, von Boehmer L, Knuth A, Ochsenbein AF, et al. Immunologic response to the survivin-derived multi-epitope vaccine EMD640744 in patients with advanced solid tumors. Cancer Immunol Immunother. 2014;63(4):381-94.

\section{Submit your next manuscript to BioMed Central and we will help you at every step:}

- We accept pre-submission inquiries

- Our selector tool helps you to find the most relevant journal

- We provide round the clock customer support

- Convenient online submission

- Thorough peer review

- Inclusion in PubMed and all major indexing services

- Maximum visibility for your research

Submit your manuscript at www.biomedcentral.com/submit
C Biomed Central 